HEAD AND NECK

\title{
Applications of intraoperative angiography in head and neck reconstruction
}

\author{
Utilizzo dell'angiografia intraoperatoria nella ricostruzione del distretto testa-collo \\ Axel Sahovaler',2, Tommaso Gualtieri2,3, John J.W. Lee', Antoine Eskander¹, Konrado Deutsch¹, Sabrina Rashid', \\ Mario Orsini ${ }^{1}$, Alberto Deganello ${ }^{3}$, Joel Davies ${ }^{1}$, Danny Enepekides ${ }^{1}$, Kevin Higgins ${ }^{1}$ \\ ${ }^{1}$ Department of Otolaryngology - Head and Neck Surgery and Surgical Oncology, Sunnybrook Odette Cancer Centre, University \\ of Toronto, Toronto, Ontario, Canada; ${ }^{2}$ Guided Therapeutics (GTx) Program, Techna Institute, University Health Network, Toronto, \\ Ontario, Canada; ${ }^{3}$ Unit of Otorhinolaryngology - Head and Neck Surgery, Department of Medical and Surgical Specialties, \\ Radiological Sciences and Public Health, University of Brescia, Brescia, Italy
}

\section{SUMMARY}

Objective. Laser-assisted angiography with indocyanine green (LAIG) allows objective intraoperative evaluation of tissue vascularity. We endeavored to describe our experience with this technique in the head and neck region.

Methods. A retrospective review from February 2016 till October 2018 was conducted. We included patients who underwent head and neck procedures in which LAIG was employed. The main outcome was postoperative wound complications. We analysed the influence of LAIG results in intraoperative decision-making process.

Results. Nineteen patients were included, and follow-up was for at least 6 months. LAIG was employed in 11 local flaps, 9 free flaps and 6 cases of pharyngeal closure during total laryngectomies. Wound complications occurred in two cases with distal tip flap necrosis. LAIG findings resulted in changes in decision making intraoperatively in $84 \%$ of procedures, which consisted in trimming poorly perfused tissues. There were no pharyngocutaneous fistulas.

Conclusions. This represents a descriptive report on the use of LAIG on diverse head and neck reconstruction cases, with important impact on the decision-making process. A low number of postoperative wound complications were observed.

KEY WORDS: laser-assisted angiography head and neck cancer, skin necrosis, indocyanine green, SPY

\section{RIASSUNTO}

Obiettivi. La tecnica LAIG (Laser-assisted angiography with indocyanine green) permette una valutazione intraoperatoria della vascolarizzazione tissutale. Con questo studio vogliamo condividere la nostra esperienza con tale tecnica nel distretto testa collo.

Metodi. È stata condotta un'analisi retrospettiva che include pazienti sottoposti a chirurgia del distretto testa-collo con utilizzo di LAIG intraoperatorio. È stata valutata l'incidenza di complicanze postoperatorie della ferita chirurgica e l'influenza dell'utilizzo di LAIG intraoperatorio nel processo decisionale del chirurgo.

Risultati. Diciannove pazienti sono stati inclusi con follow-up minimo di 6 mesi. LAIG è stata applicata su 11 lembi locali, 9 lembi liberi ed in 6 casi di chiusura del faringe post laringectomia totale. In due casi la necrosi distale del lembo ha portato a complicanze correlate alla ferita chirurgica. LAIG ha portato a modificazione del processo decisionale intraoperatorio nell' $84 \%$ dei casi.

Conclusioni. Questo studio descrittivo dimostra la applicabilità di LAIG in diverse procedure ricostruttive nel distretto testa-collo, con un impatto importante sul processo decisionale intraoperatorio ed una bassa incidenza di complicanze della ferita chirurgica.

PAROLE CHIAVE: angiografia laser-assistita, cancro del distretto testa-collo, necrosi cutanea, verde indocianina, SPY
Received: October 5, 2020

Accepted: November 20, 2020

\section{Correspondence}

Kevin Higgins

Department of Otolaryngology - Head \& Neck

Surgery, University of Toronto, Sunnybrook Health Sciences Centre

2075 Bayview Avenue, M-wing, $1^{\text {st }}$ floor, room M1 102, Toronto, ON M4N 3M5, Canada

E-mail: kevin.higgins@sunnybrook.ca

Funding

None.

\section{Conflict of interest}

The Authors declare no conflict of interest.

How to cite this article: Sahovaler A, Gualtieri $\mathrm{T}$, Lee JJW, et al. Applications of intraoperative angiography in head and neck reconstruction. Acta Otorhinolaryngol Ital 2021;41:215-220. https://doi.org/10.14639/0392-100X-N1161

() Società Italiana di Otorinolaringoiatria e Chirurgia Cervico-Facciale

\section{(c) (1) $(9)$}

This is an open access article distributed in accordance with the CC-BY-NC-ND (Creative Commons Attribution-NonCommercial-NoDerivatives 4.0 International) license. The article can be used by giving appropriate credit and mentioning the license, but only for non-commercial purposes and only in the original version. For further information: https:// creativecommons.org/licenses/by-nc-nd/4.0/deed.en 


\section{Introduction}

Without appropriate tissue perfusion even the most elegant reconstruction can be doomed for failure. In head and neck surgery, employing vitally compromised tissues for reconstruction can have substantial consequences both functionally and aesthetically. Traditionally, tissue viability has been assessed using a combination of clinical observation and surgical expertise. This method lacks inherent objectivity, reliability and reproducibility ${ }^{1}$.

Laser-assisted angiography with indocyanine green (ICG) dye utilises a near-infrared (NIR) imaging system that provides an intraoperative visual assessment of blood flow within tissues. The ICG molecule possess high affinity to plasma proteins, remaining entirely bound within the intravascular space, which makes it suitable to evaluate perfusion. It is metabolised by the liver and excreted in the kidneys, without any hepatic or renal toxic effects, with a short half-life of 3 to 5 minutes. The risk of anaphylactic reaction is low and is associated with iodine allergy. When the ICG molecules are exposed to light and excited in the NIR spectrum, tissue perfusion can be evaluated by identification and quantification of the fluorescence intensity of the particles: well-perfused tissue appear fluorescent and ischemic tissue appears dark. Post-imaging annotation software present in the NIR devices can analyse results qualitatively and quantitively, decreasing subjectivity and increasing interobserver reliability. This technology has been widely implemented in breast surgery, where authors highlighted the decrease in the occurrence of post-mastectomy necrosis and subsequent implant loss ${ }^{2-6}$, as it allowed to identify and remove poorly vascularised tissue.

Nowadays, this technique is not as widely used in head and neck reconstructive surgery, even though there have been prior publications highlighting its benefits ${ }^{7-10}$. The objective of this study was to communicate our initial experience using laser-assisted angiography with ICG (LAIG) in major head and neck reconstructive procedures, describing the range of applications and report our rates of postoperative wound complications.

\section{Materials and methods}

A retrospective review from February 2016 till October 2018 at Sunnybrook Health Science Center was conducted. We only included patients who underwent a major head and neck procedure in which LAIG was employed. The decision to employ this technology in certain cases was purely made based on the availability of the equipment as it is mainly used by plastic surgery at our centre. Patient demographics, along with tumour histology, location, type of defect, previous treatment and reconstruction modality were accounted for. In addition, we also calculated the extra-costs and added time to the procedures. Costs were calculated based on total coded and non-coded billing information and contacting the pharmacy department, and time was calculated using a timer feature of the software after the ICG injection. Main outcome was postoperative wound complications (defined as any wound healing complication within 30 days after the surgery). We also analysed if LAIG results affected the intraoperative decision-making process. Research ethics board approval was obtained from Sunnybrook Health Sciences Centre (REB\# 21-709.12).

\section{LAICG Dye Angiography Protocol}

Before using ICG, all patients were evaluated for an iodine or shellfish allergy. The SPY Elite machine (Novadaq Technologies, Mississauga, Ontario, Canada) is sterilely draped and the area of interest if visualised. Three $\mathrm{ml}$ of the reconstituted ICG is injected peripherally and followed by a $10 \mathrm{ml}$ saline flush. Recording of the tissue of interest then commences. In the case of pedicled flaps, recording is done after flap elevation, to confirm adequate vascularisation of the tissue especially at the distal edges. In the case of free flaps, LAIG was used in addition to the hand held doppler to select the most suitable perforator (in Anterolateral Thigh -ALT- flaps), and before completing the flap elevation, to ensure that the selected perforator/s provided adequate vascularisation. It was also used in cases where free flaps were trimmed after their elevation (ALT, Temporoparietal fascia free flap and latissimus dorsi). In post-pharyngectomy cases, the edges of native pharyngeal mucosa, which are high risk areas for fistula formation are evaluated. Areas of concern were considered poorly perfused if, at 45-60 seconds after injection and flush of the IG, the intensity of the site by LAIG was $33 \%$ or less of a well perfused area set as a control on the SPY software. This threshold value was determined following previous reports of the literature ${ }^{11,12}$. The poorly perfused area was marked and trimmed back to confirmed well perfused tissue.

\section{Results}

Intraoperative angiography was employed in 19 patients (Tab. I). The average patient age was 65 years (range 35 to 84 ) and 14 were male. All but two cases were operated on for malignant disease; one trauma and one osteoradionecrosis case. LAIG was employed in eleven cases of local flaps, nine cases of free flaps and six cases of pharyngeal closure (three of these were salvage laryngectomies). Of note, LAIG was utilised for assessment in more than one type of reconstruction. The added cost to the procedure by the use of this technology was 30 USD as the ICG is non- 
Table I. Patients in which LAIG was employed.

\begin{tabular}{|c|c|c|c|c|c|c|c|c|}
\hline Pt & Age & Gender & Pathology & Defect Location & $\begin{array}{l}\text { Previous } \\
\text { treatment }\end{array}$ & Reconstructive strategy & $\begin{array}{c}\text { LAIG } \\
\text { modified } \\
\text { approach }\end{array}$ & $\begin{array}{l}\text { Wound } \\
\text { complications }\end{array}$ \\
\hline 1 & 69 & M & Cutaneous SCC & Scalp & & Lat & + & - \\
\hline 2 & 64 & $\mathrm{~F}$ & Metastatic SCC parotid & Preauricular skin & & SCAIF & + & - \\
\hline 3 & 75 & M & $\mathrm{BCC}$ & Cervical skin & & ALT & + & - \\
\hline 4 & 35 & M & Trauma & T-E fistula & & TPFF & + & - \\
\hline 5 & 69 & M & $\begin{array}{c}\text { Supraglottic SCC } \\
\text { (T4aN2C) }\end{array}$ & $\begin{array}{c}\text { Partial } \\
\text { Pharyngectomy }\end{array}$ & & $\begin{array}{c}\text { ALT/ } 1^{\text {ary }} \text { pharyngeal } \\
\text { closure }\end{array}$ & + & $\begin{array}{l}\text { Distal tip necrosis } \\
\text { of ALT skin paddle }\end{array}$ \\
\hline 6 & 60 & $\mathrm{~F}$ & $\begin{array}{c}\text { Supraglottic SCC } \\
\text { (T3N1) }\end{array}$ & $\begin{array}{c}\text { Partial } \\
\text { Pharyngectomy }\end{array}$ & + & 1ary Pharyngeal closure & + & - \\
\hline 7 & 80 & M & Melanoma & Preauricular skin & & SCAIF & + & - \\
\hline 8 & 60 & M & $\begin{array}{c}\text { Supraglottic SCC } \\
\text { (T4aN2a) }\end{array}$ & $\begin{array}{c}\text { Partial } \\
\text { Pharyngectomy }\end{array}$ & & $\begin{array}{l}\text { TPFF/1 ary pharyngeal } \\
\text { closure }\end{array}$ & + & - \\
\hline 9 & 58 & M & $\mathrm{BCC}$ & Preauricular skin & & Fascial RFFF & - & - \\
\hline 10 & 51 & M & Cutaneous SCC & Cervical skin & & SCAIF & + & - \\
\hline 11 & 52 & M & Oral cavity SCC & $\begin{array}{l}\text { Through-through } \\
\text { buccal mucosa }\end{array}$ & & ALT/Cervicofacial & + & $\begin{array}{l}\text { Distal tip necrosis } \\
\text { of cervicofacial }\end{array}$ \\
\hline 12 & 84 & $\mathrm{~F}$ & $\mathrm{BCC}$ & Forehead & & Pericranium & - & - \\
\hline 13 & 52 & $\mathrm{~F}$ & Cutaneous SCC & Preauricular skin & & Cervicofacial & + & - \\
\hline 14 & 67 & M & Osteoradionecrosis & Scalp/Calvarial bone & & Lat/Cervicofacial & + & - \\
\hline 15 & 53 & M & $\begin{array}{c}\text { Hypopharyngeal SCC } \\
\text { (T3N2b) }\end{array}$ & $\begin{array}{c}\text { Partial } \\
\text { Pharyngectomy }\end{array}$ & + & $\begin{array}{l}\text { ALT/1 } 1 \text { ary pharyngeal } \\
\text { closure }\end{array}$ & + & - \\
\hline 16 & 92 & M & Mucoepidermoid parotid & Preauricular skin & & SCAIF & + & - \\
\hline 17 & 71 & M & $\begin{array}{c}\text { Hypopharyngeal SCC } \\
\text { (T4N1) }\end{array}$ & $\begin{array}{c}\text { Partial } \\
\text { Pharyngectomy }\end{array}$ & & Pharyngeal closure & + & - \\
\hline 18 & 79 & $\mathrm{~F}$ & Supraglottic SCC (T3N1) & $\begin{array}{c}\text { Partial } \\
\text { Pharyngectomy }\end{array}$ & + & $\begin{array}{l}\text { SCAIF } / 1^{\text {ary }} \text { pharyngeal } \\
\text { closure }\end{array}$ & + & - \\
\hline 19 & 61 & M & Cutaneous SCC & Preauricular skin & & SCAIF/Cervicofacial & - & - \\
\hline
\end{tabular}

T-E: tracheoesophageal fistula; Lat: latissimus dorsi free flap; ALT: anterolateral thigh free flap; SCAIF: supraclavicular artery island flap; TPFF: temporalis fascia free flap; SCC: squamous cells carcinoma; BCC: basal cells carcinoma.

proprietary and the pharmacy department facilitated it for us. Regarding the extra time consumed, the total operation was prolonged by an average of 13 minutes.

LAIG findings resulted in changes in decision-making intraoperatively in $84 \%$ of the cases: tissues were trimmed when poor distal perfusion was observed in cases of local, free tissue transfer and native pharyngeal mucosa. Minor wound complications occurred in two cases: distal tip flap necrosis in an anterolateral thigh free flap and in a cervicofacial advancement flap. These were managed conservatively. There were no pharyngocutaneous fistulas or total free flap loss.

\section{Example 1}

61-year-old male with a neglected preauricular cutaneous squamous cell carcinoma. The patient underwent wide excision of the skin, superficial parotidectomy and neck dissection. To reconstruct the defect a supraclavicular artery island flap (SCAIF) and a cervicofacial advancement flap to replace the skin defect were employed. Both flaps were evaluated using the SPY system confirming good vascularisation. No wound complications were noted at follow up. In this case the distal tip of the cervicofacial advancement flap appeared dusky and had venous flow from the subdermal plexus, but had robust amplified ICG perfusion with values over the threshold so it was left intact.

\section{Example 2}

35-year-old quadriplegic male initially injured in a snowboarding accident in 2009. Shortly after injury he required anterior and posterior fusion to stabilise his c-spine. Unfortunately, the anterior plate eroded through his oesphagus creating a trachea-oesophageal fistula which healed as a large laryngeal cleft preventing oral intake. A TPFF was utilised to reconstruct the defect. The flap was divided into leaflets and LAIG confirmed adequate blood supply. 
This allowed reliable customisation of TPFF in order to reestablish the tridimensional pharyngeal framework, with a fascial flap typical difficult to assess vascularisation. After the microvascular anastomosis, the flap had continued perfusion and the patient had an uncomplicated postoperative course (Fig. 1).

\section{Example 3}

60 -year-old female diagnosed with a T3N1 supraglottic squamous cell carcinoma who previously received chemoradiation as part of an organ preservation strategy. Unfortunately, the tumour recurred mandating a salvage surgical approach. LAIG was used to evaluate the pharyngeal strip after tumour extirpation. The SPY system suggested an area of poor perfusion and the mucosa was trimmed to healthy tissue (Fig. 2). The patient had an uneventful postoperative course.

\section{Discussion}

In the head and neck surgical oncology setting, wound complications after reconstructive procedures may lead to catastrophic consequences. Even minor cases of flap necrosis that can be managed conservatively may lead to suboptimal aesthetic results and affect quality of life. In cases of pharyngeal and oral cavity reconstructions, salivary fistulas cause delayed oral intake, and can result in lifethreatening conditions such as carotid blow-out syndrome. Reconstruction failures can also indirectly impact on patient prognosis as they may delay the initiation of adjuvant treatment ${ }^{13,14}$. Advocators for the use of LAIG highlight its ability to provide real-time intraoperative and objective assessment of areas of tissue perfusion that are not identified by the surgeon, serving as a superior clinical indicator compared with clinical intraoperative judgement alone ${ }^{15}$. There is extensive breast reconstructive literature reporting the advantages of this technology ${ }^{3,5}$, where a reduction in post-mastectomy necrosis rates was found and therefore in implant loss ${ }^{3,6}$. In addition, it has been reported that the use of LAIG had an impact in decision-making intraoperatively in reconstructive surgery ${ }^{10}$. However, in head and neck surgery this technique is not routinely used. We endeavored to report the use of LAIG in a variety of clinical scenarios in head and neck reconstruction.

Necrosis of the distal tip of the flap is the most common complication when using large locoregional fasciocutaneous flaps that extend beyond their vascular pedicle primary and adjacent angiosomes ${ }^{16}$. Cervicofacial flaps and SCAIF have a $9 \%{ }^{17}$ and $18 \%{ }^{18}$ risk of partial necrosis respectively. A recent survey capturing 221 head and neck surgeons revealed that the rate of complications with SCAIF was $29.8 \%{ }^{19}$. In our series when using SCAIF we experienced only one distal tip necrosis $(16,6 \%)$, and no complications were reported when using cervicofacial flaps.

In free-flaps with high perforator variability such as the anterolateral thigh (ALT) free flap ${ }^{20}$, intraoperative angiography was described as an adjunct to select the most reliable skin perforator, as well as allowing reliable trimming prior to harvesting with good results ${ }^{21}$. Although we did not utilise LAIG for any fibula flap, Beckler et al. ${ }^{13}$ also had very promising results with the intraoperative angiography approach observing a reduction in partial skin flap necrosis of fibula flaps in a cohort of 73 patients that un-

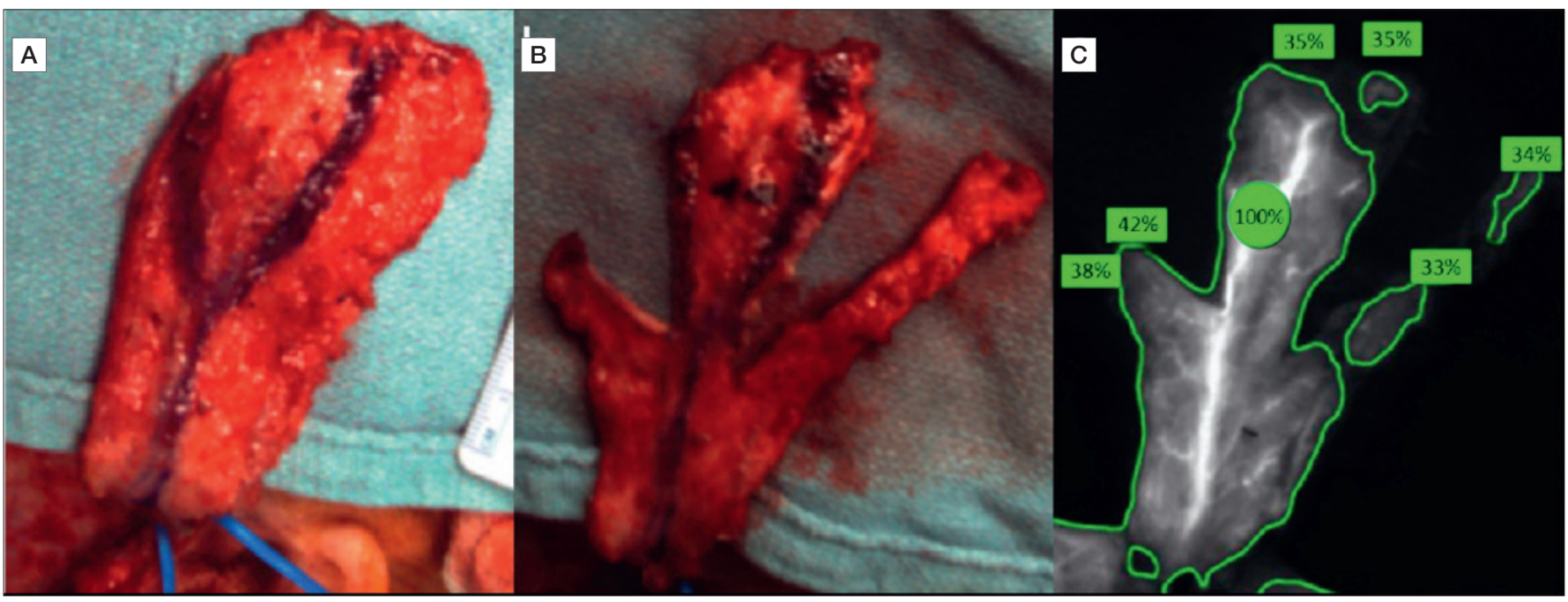

Figure 1. (A) Temporoparietal fascial free flap harvested to reconstruct the defect; (B) TPFFF divided into leaflets for reconstructive purposes; (C) LAIG analysis on TPFFF confirming adequate blood supply in all its regions. 


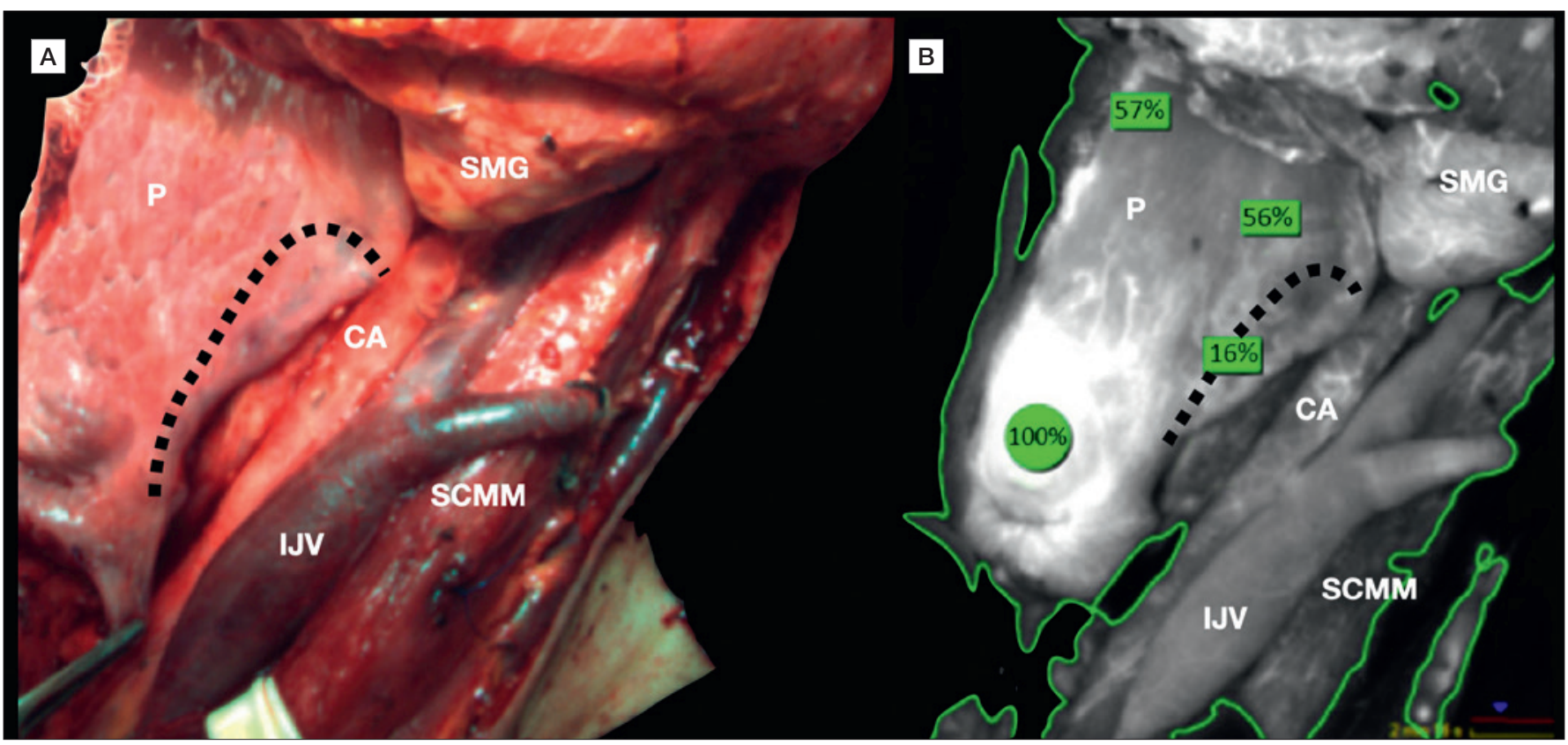

Figure 2. (A) Intraoperative picture showing a poorly perfused left pharyngeal area after tumour resection; (B) LAIG analysis showed an area of poor perfusion (black dotted line). P: pharyngeal remnant; SMG: submandibular gland; CA: carotid artery; IJV: internal jugular vein; SCMM: sternocleidomastoid muscle.

derwent oromandibular reconstructions with through and through defects.

The reported post-laryngectomy pharyngocutaneous fistula rates range between $16 \%$ to $65 \%{ }^{22}$. Two prospective studies including 37 and 41 patients respectively, compared mucosal perfusion detected by this technology in salvage laryngectomies and found that patients who developed postoperative fistulas had lower mucosal perfusion values when compared with patients who did not develop fistulas ${ }^{12,23}$, suggesting that there might be a role for LAIG in assessing vascularisation of the pharyngeal mucosa remnant. In the same line as these two last reports, we did not experience any pharyngocutaneous fistulas after pharyngectomies.

Limitations of this study are a small sample size, the retrospective nature of the study, lack of a control group, and the absence of a formal statistical analysis. Nevertheless, it represents a valuable descriptive series highlighting the versatility of the use of LAIG in head and neck reconstruction. It is also important to consider the cost of this technology. In many tertiary-care centres the system is already available as it is largely employed in breast surgery, so the cost centres around the indocyanine green. If the ICG or the equipment are not readily available, the cost can escalate, being 650 USD according to Kanuri et al. ${ }^{24}$. Regarding added time spent in the operating room, it is not a timeconsuming procedure, and the average in our series was 13 minutes since the time of the ICG injection.

\section{Conclusions}

We employed LAIG in a diverse range of head and neck oncologic and reconstruction applications with encouraging results. Postoperative wound complications were limited $(10 \%)$ and were all managed successfully with conservative strategies. This technology determined a change in decision making of the surgeon in a high percentage of the procedures. Subsequent studies evaluating its application in head and neck surgery are required to validate our findings.

\section{References}

Eskander A, Kang S, Tweel B, et al. Predictors of complications in patients receiving head and neck free flap reconstructive procedures. Otolaryngol Head Neck Surg 2018;158:839-847. https://doi. org/10.1177/0194599818757949

2 Komorowska-Timek E, Gurtner GC. Intraoperative perfusion mapping with laser-assistedindocyanine green imaging can predict and preventcomplications in immediate breast reconstruction. Plast Reconstr Surg 2010;125:1065-1073. https://doi.org/10.1097/ PRS.0b013e3181d17f80

3 Newman MI, Samson MC. The application of laser-assisted indocyanine green fluorescent dye angiography in microsurgical breast reconstruction. J Reconstr Microsurg 2009;25:21-26. https://doi. org/10.1055/s-0028-1090617

4 Pestana IA, Coan B, Erdmann D, et al. Early experience with fluorescent angiography in free-tissue transfer reconstruction. Plast Reconstr Surg 2009;123:1239-1244. https://doi.org/10.1097/ PRS.0b013e31819e67c1

5 Phillips BT, Lanier ST, Conkling N, et al. Intraoperative perfu- 
sion techniques can accurately predict mastectomy skin flap necrosis in breast reconstruction: results of a prospective trial. Plast Reconstr Surg 2012;129:778e-88e. https://doi.org/10.1097/ PRS.0b013e31824a2ae8

6 Mirhaidari SJ, Beddell GM, Orlando M V, et al. A prospective study of immediate breast reconstruction with laser-assisted indocyanine green angiography. Plast Reconstr Surgery Glob Open 2018;6:e1774. https://doi.org/10.1097/GOX.0000000000001774

7 Woodard CR, Most SP. Intraoperative angiography using laser-assisted indocyanine green imaging to map perfusion of forehead flaps. Arch Facial Plast Surg 2012;14:263-269. https://doi.org/10.1001/ archfacial.2011.1540

8 Abdelwahab M, Kandathil CK, Most SP, et al. Utility of indocyanine green angiography to identify clinical factors associated with perfusion of paramedian forehead flaps during nasal reconstruction surgery. JAMA Facial Plast Surg 2019;21:206-212. https://doi. org/10.1001/jamafacial.2018.1829

9 Hitier M, Cracowski J-L, Hamou C, et al. Indocyanine green fluorescence angiography for free flap monitoring: a pilot study. J CranioMaxillofacial Surg 2016;44:1833-1841. https://doi.org/10.1016/j. jems.2016.09.001

10 Moris V, Cristofari S, Stivala A, et al. Fluorescent indocyanine green angiography: Preliminary results in microsurgery monitoring. J Stomatol Oral Maxillofac Surg 2019;120:297-300. https://doi. org/10.1016/j.jormas.2019.07.006

11 Moyer HR, Losken A. Predicting mastectomy skin flap necrosis with indocyanine green angiography. Plast Reconstr Surg 2012;129:10431048. https://doi.org/10.1097/PRS.0b013e31824a2b02

12 Partington EJ, Moore LS, Kahmke R, et al. Laser-assisted indocyanine green dye angiography for postoperative fistulas after salvage laryngectomy. JAMA Otolaryngol Neck Surg 2017;143:775. https:// doi.org/10.1001/jamaoto.2017.0187

13 Beckler AD, Ezzat WH, Seth R, et al. Assessment of fibula flap skin perfusion in patients undergoing oromandibular reconstruction: comparison of clinical findings, fluorescein, and indocyanine green angiography. JAMA Facial Plast Surg 2015;17:422-426. https://doi. org/10.1001/jamafacial.2015.0961

14 Graboyes EM, Garrett-Mayer E, Ellis MA, et al. Effect of time to initiation of postoperative radiation therapy on survival in surgically managed head and neck cancer. Cancer 2017;123:4841-4850. https:// doi.org/10.1002/cncr.30939
15 Mothes H, Dönicke T, Friedel R, et al. Indocyanine-green fluorescence video angiography used clinically to evaluate tissue perfusion in microsurgery. J Trauma 2004;57:1018-1024. https://doi.org/10.1097/01. ta.0000123041.47008.70

16 Said M, Heffelfinger R, Sercarz JA, et al. Bilobed fibula flap for reconstruction of through-and-through oromandibular defects. Head Neck 2007;29:829-834. https://doi.org/10.1002/hed.20612

17 Moore BA, Wine T, Netterville JL. Cervicofacial and cervicothoracic rotation flaps in head and neck reconstruction. Head Neck 2005;27:1092-1101. https://doi.org/10.1002/hed.20252

18 Sukato DC, Timashpolsky A, Ferzli G, et al. Systematic review of supraclavicular artery island flap vs free flap in head and neck reconstruction. Otolaryngol Head Neck Surg 2019;160:215-222. https:// doi.org/10.1177/0194599818803603

19 Day AT, Tang L, Emerick K, et al. Supraclavicular flap practice patterns and outcomes: A survey of 221 AHNS surgeons. Laryngoscope 2019;129:2012-2019. https://doi.org/10.1002/lary.27641

20 Deng C, Nie K, Wei Z, et al. Is the oblique branch a preferable vascular pedicle for anterolateral thigh free flaps? J Reconstr Microsurg 2018;34:478-484. https://doi.org/10.1055/s-0038-1639370

21 La Padula S, Hersant B, Meningaud JP. Intraoperative use of indocyanine green angiography for selecting the more reliable perforator of the anterolateral thigh flap: a comparison study. Microsurgery 2018;38:738-744. https://doi.org/10.1002/micr.30326

22 Sharaf B, Xue A, Solari MG, et al. Optimizing outcomes in pharyngoesophageal reconstruction and neck resurfacing: 10-year experience of 294 cases. Plast Reconstr Surg 2017;139:105e-119e. https:// doi.org/10.1097/PRS.0000000000002915

23 Hoesli R, Brennan JR, Rosko AJ, et al. Intraoperative fluorescent angiography predicts pharyngocutaneous fistula after salvage laryngectomy. Ann Surg Oncol 2019;26:1320-1325. https://doi.org/10.1245/ s10434-019-07262-6

24 Kanuri A, Liu AS, Guo L. Whom should we SPY? A cost analysis of laser-assisted indocyanine green angiography in prevention of mastectomy skin flap necrosis during prosthesis-based breast reconstruction. Plast Reconstr Surg 2014;133:448e-454e. https://doi. org/10.1097/PRS.0000000000000025 